\title{
O uso de imagens nas aulas de FLE para crianças
}

\author{
Naraina de Melo Martins Kuyumjian ${ }^{1}$
}

Resumo: Este artigo apresenta quatro possibilidades de exploração de imagens como recurso pedagógico para aulas de língua estrangeira para crianças. O objetivo é explicitar os diferentes usos que podem ser feitos da imagem em aulas de língua estrangeira para criança de forma a promover e estruturar a produção oral dos aprendizes dentro de uma prática pedagógica significativa e autêntica. Por estar situado na interface linguística e pedagógica apresentamos algumas precisões sobre o lugar da manipulação de objetos na aquisição de uma palavra.

Palavras-chave: Imagens. Oralidade. Ensino-aprendizagem. FLE para crianças.

\section{The use of images in FLL classes for children}

\begin{abstract}
This article presents four possibilities for the use of image as an educational resource for foreign language classes for children. The goal is to explain the different uses that can be made of the image in foreign language classes for children in order to promote and structure the production of oral learners within a significant and authentic pedagogical practice. Being located in linguistics and pedagogy interface some details of the place of object manipulation in acquiring a word is given.
\end{abstract}

Key words: Images. Oral communication. Teaching and learning. FLE for children.

\section{Introdução}

Este artigo é um produto da pesquisa de mestrado intitulada "O Ensino do Francês como Língua Estrangeira para crianças Brasileiras: uma proposta metodológica" defendida em dezembro de 2014 no departamento de Linguística Aplicada da Universidade de Brasília. Foi durante a minha experiência como professora da Educação Infantil em uma escola internacional que a pesquisa encontrou sua origem. A constatação de que muitos professores replicavam metodologias e didáticas usadas com crianças mais velhas nas salas da Educação Infantil revelou uma problemática que pode ser traduzida por uma pergunta. Como o professor pode promover um ensino efetivo e significativo da língua estrangeira para crianças de 3 a 6 anos? No processo de busca o uso de imagens revelou-se uma importante ferramenta pedagógica para aulas centradas na produção oral.

\footnotetext{
${ }^{1}$ Doutoranda do CNRS - Laboratório PRAXILING, Universidade Paul-Valery, Montpellier, França.
} 
O objetivo primeiro deste artigo está, portanto, em explicitar algumas possíveis explorações de imagens como recurso pedagógico para a faixa etária em questão. Enfoca-se, para tanto, os aspectos linguísticos já que busca-se favorecer a expressão oral dos alunos por meio da superação das lacunas linguísticas. Como segundo objetivo espera-se poder contribuir com as práticas educativas de outros professores de língua estrangeira centradas no oral.

O texto está organizado em três partes. Primeiramente explicita-se as concepções de língua e de oralidade consideradas nestas páginas. Em segundo lugar, o lugar da manipulação é apontada a partir do processo trabalhado por Vygotsky de apropriação de uma palavra. Uma sistematização de quatro possibilidades de uso pedagógico da imagem constitui o terceiro item.

\section{Considerações iniciais: concepção de língua e de oralidade}

No livro Marxismo e a Filosofia da Linguagem, Bakhtin (VOLOSHINOV, 1992) descreve a língua como sendo viva, que evolui historicamente, que deve ser compreendida no seu contexto de uso e é ideológica. Estas características da língua permitem buscar nas situações de ensino-aprendizagem a comunicação como necessidade genuína gerada a partir de situações problemas adaptados e de interesse do aprendiz. A língua não é, portanto, pensada na sua estrutura interna ou dentro de um ideal imaginado que se busca alcançar, mas nas ilimitadas possibilidades que ela, a partir de um número limitado de signos, possui para expressar os pensamentos e as ideias no seu potencial de criação.

As duas modalidades da língua, a fala e a escrita não são, no entanto, consideradas dentro de uma relação dicotômica, mas, sim, dentro de um contínuo (MARCUSCHI, 2010, p.27). Podemos, desta forma, conceber diversos tipos de relações do oral com a escrita, não existindo linha divisória estanque, mas, ao contrário, um permanente diálogo entre elas. O foco, no entanto, tanto da pesquisa de mestrado quanto deste artigo, é a oralidade, dada a idade dos aprendizes e do desejo em contribuir com a retomada de fôlego que este aspecto da língua, nas suas diversas dimensões, tem ganhado recentemente.

A oralidade é compreendida como uma prática social interativa para fins comunicativos que se apresenta sob variadas formas ou gêneros textuais fundados na realidade sonora; ela vai desde uma realização mais informal à mais formal nos mais variados contextos de uso 
(MARCUSCHI, 2010, p. 25). Segundo Marcuschi (2010), a fala é uma forma de oralidade. A oralidade é uma prática social que pode usar diversos meios para ser transmitida e a fala é uma forma de produção que usa a voz produzida pelo homem sem o uso de tecnologias.

Assim sendo, os exemplos que seguirão estão no plano da oralidade já que abarcam uma grande diversidade de formas de produção do oral, como a fala das crianças e da professora, filmes disponíveis na internet e material audiovisual gravados durante as aulas.

\section{Como aprendemos uma palavra?}

A faixa etária considerada (crianças de 3 a 6 anos) traz consigo dois aspectos que o professor deve levar em conta. Primeiramente a centralidade da modalidade oral. Mesmo que a escrita esteja presente (e deve estar) nas atividades propostas e nos espaços das aulas ela não ocupa um lugar central. A ênfase é dada ao oral simplesmente pela primazia cronológica que esta modalidade apresenta no desenvolvimento comunicativo do indivíduo. É possível estruturar, complexificar e apresentar uma diversidade de práticas e gêneros orais antes de focar os esforços na escrita. É oralmente que a criança irá pela primeira vez se expressar, se reconhecer e reconhecer o outro, nomear o mundo que lhe rodeia...

O segundo aspecto lembra que a aprendizagem da língua acontece juntamente e completamente imbricada com todos os outros processos de desenvolvimento. Gostaríamos de refletir sobre o lugar do desenvolvimento cognitivo e corporal no processo de ensinoaprendizagem de uma língua. Veremos, com a ajuda de Vygotsky que é fundamental que a aula seja capaz de propiciar momentos que envolvam o uso do corpo, o movimento e a manipulação.

Vygotsky, no seu livro Pensamento e Linguagem (2008), descreve como uma criança aprende uma palavra. $\mathrm{O}$ sentido da apreensão de uma palavra vai do concreto para o abstrato. $\mathrm{Na}$ sua primeira fase a criança constrói aquilo que o autor chama de complexo. O complexo é uma generalização possibilitada pela manipulação de objetos concretos. Vygotsky (2008) ressalta que todas as atividades ou exercícios que vão interferir em grupos de objetos contribuem para a construção do complexo que possui um processo que lhe é próprio. A criança identifica as diferenças em um primeiro momento e, posteriormente, as semelhanças entre os objetos, apenas e, do conceito na presença do signo, que é a palavra.

A fase seguinte é a construção do conceito que por sua vez é abstrata. Palavras expressam generalizações. Na primeira vez em que a criança diz "cachorro", por exemplo, ela associa essa 
palavra a uma imagem. No entanto, existem vários tipos de cachorros, diferentes no tamanho, na cor, na forma. A criança ainda não possui uma ideia generalizada do signo. Por tentativa e erro, ela tenta incorporar mais imagens ao signo "cachorro". Ao ver um gato, ela poderá dizer, por exemplo, "cachorro"; ao ver uma mesa, ela poderá dizer "cachorro". É então com a mediação de um adulto que o conceito vai se construindo, dentro de uma lógica binária, "cachorro" e "não cachorro". As diferentes imagens vão sendo agregadas ou excluídas de um grupo, ou seja, categorizadas.

A palavra é o elemento central nesse processo que nasce com uma tarefa concreta e encontra, na abstração, a sua última fase. A formação dos conceitos não é, então, o resultado de um processo mecânico e passivo, mas de um processo criativo. É na tentativa de resolver uma situação-problema que o conceito surge e se configura.

O processo descrito acima permite entender o papel da experiência concreta e do vínculo que a língua possui com o contexto histórico e social, ou seja, com a cultura do lugar onde ela foi aprendida. O linguista Claude Hagège sintetiza bem esta relação entre palavra e mundo concreto.

Ceux, parmi les noms, qui désignent des objets sont les éléments de langue que l'enfant apprend le plus facilement, car ces objets font partie de son environnement. C'est pourquoi l'accroissement du vocabulaire est directement relié à la connaissance du monde. Les langues ne sont pas de schèmes sans matière. Elles parlent de l'univers, le reflètent et l'organisent, même si c'est à travers des grilles variables selon les cultures. (HAGÈGE, 2005, p.65) ${ }^{2}$

Chamamos a atenção para o fato de que um trabalho que visa o oral não é um trabalho feito exclusivamente no oral. Concluímos desta forma que a utilização de materiais concretos é pertinente em um trabalho centrado no oral. Levando em consideração os aspectos levantados acima, o uso da imagem como recurso pedagógico ganha espaço e importância.

\section{O Uso De Imagens}

As discussões desenvolvidas até o momento evidenciam alguns conceitos e abordagens centrais para o desenvolvimento de uma didática específica. As imagens se revelaram uma

\footnotetext{
${ }^{2}$ Tradução livre: Os nomes que designam objetos são aqueles que a criança aprende com maior facilidade já que estes objetos fazem parte do seu meio. É por esta razão que o aumento do repertório lexical está diretamente relacionado ao conhecimento do mundo. As línguas não são esquemas sem matéria. Elas falam do universo, elas o refletem e o organizam, mesmo que através lentes variáveis segundo a cultura.
} 
ferramenta muito interessante neste processo, tanto pedagógica quanto linguisticamente. Pontuarei a seguir quatro possibilidades de trabalho que a imagem fornece e que foram exploradas na pesquisa.

A. Apropriar-se de um espaço, seja ele virtual ou não;

B. Associar som e significado, ou seja, um trabalho voltado para o enriquecimento do acervo lexical;

C. Explicitar não somente o que é visto e facilmente identificado, como objetos, mas também ações e sentimentos;

D. Reviver uma situação do passado. Se podemos falar sobre um evento que está acontecendo (linguagem em situação), também podemos evocá-lo no passado e contálo àqueles que não estavam presentes (linguagem de evocação). Essas duas modalidades exigem conhecimentos linguísticos distintos e podem ser a base de uma progressão que se complexifica progressivamente.

Vou abordar, com o auxílio de exemplos, cada um dos pontos levantados acima.

O blog criança bilíngue foi criado para servir de suporte para os alunos particulares e seus pais no projeto do bilinguismo precoce. Cada grupo ou aluno possui uma página onde conteúdos diversos são sistematizados de forma a, aos poucos, por uma lado, constituir um caderno multimidiático onde podemos ver aquilo que está sendo trabalhado durante as aulas e, por outro lado, fornecer um acervo complementar de vídeos, sites e informações. Os alunos na primeira aula definiram o nome da sua página no blog, serpent (serpente). A primeira imagem utilizada foi tirada por mim das crianças para ilustrar a página de abertura da página deles. Sob a imagem, podíamos ver os links com os títulos dos temas que seriam abordados. Na ocasião, existia apenas um link, Les Animaux. Ao acessá-lo, podíamos ver uma pré-seleção feita de imagens de diversas serpentes. Este constituiu o material-base para iniciar o trabalho com as crianças. Tiramos essa foto logo no primeiro dia de aula e, já no segundo dia, iniciamos a aula cujo tema central diante da escolha do nome da página só poderia ser Les animaux (Os animais). 
Ao ver a sua própria imagem na página de abertura que lhes era destinada, bem como as imagens que remetiam ao animal que eles mesmos tinham escolhido na aula anterior como suporte de trabalho, as crianças se reconheceram nesse espaço do qual, consequentemente, apropriaram-se gradativamente. Aos poucos, com a publicação dos outros materiais, percebeu-se, por um lado, que aquilo que estava sendo desenvolvido na aula fora preparado para eles, respeitando as suas necessidades, particularidades e usando as suas contribuições. Por outro lado, entendeu-se que o trabalho que estava sendo desenvolvido durante as aulas teria uma repercussão no blog.

O entusiasmo demonstrado já na segunda aula e, posteriormente, a pergunta que apareceu reiteradas vezes - "Isto vai pro blog?" - são indícios desta motivação causada pela caráter ativo que os alunos assumem no seu próprio processo de aprendizagem concretizadas, neste caso, na imagens e nas fotos. A aula não representava um fim em si mesmo, nem para o professor, nem para o aluno. Existia a preocupação de fazer as tarefas de modo bem feito ou então a intencionalidade de fazer alguma travessura para que ela pudesse aparecer no blog.

Além de terem sido uma importante ferramenta para a apropriação do espaço virtual (e também do caderno) e para que os aprendizes se implicassem mais durante as aulas, as imagens também funcionavam no sentido de confirmar a compreensão de algo que tinha sido apresentado na LE. Foi esse o caso, por exemplo, para a primeira foto publicada, na medida em que explico em francês que a foto é para colocar no blog. É a repetição da frase usada ${ }^{3}$, desta vez com a visualização da foto no $b \log$, que permite confirmar a compreensão com base na realização da ação verbalizada. No caso acima, o vínculo não se dá tanto pela compreensão dos elementos linguísticos da frase. É uma compreensão mais ampla na qual, por meio de vários elementos

H 3 "Je vais prendre une photo de vous pour mettre sur le blog." ("Eu vou tirar - TINAR Salis

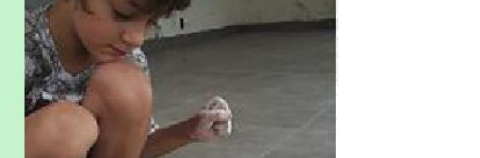


comunicativos, consegue-se apreender o sentido daquilo que está sendo dito.

A segunda possiblidade pedagógica e linguística que a imagem pode fornecer diz respeito ao vínculo que pode ser estabelecido entre som e imagem. Os dicionários de imagens 4 são exemplos de como podemos estabelecer uma relação simples e linear entre um material auditivo e visual. Um exercício desenvolvido no tema Pirates (Piratas) pode servir de exemplo. Duas atividades buscaram instrumentalizar as crianças com palavras que lhes ajudassem a se expressar dentro do tema escolhido. Como podemos visualizar nas imagens a seguir foram trabalhados alguns objetos ou elementos recorrentes nas histórias de piratas.

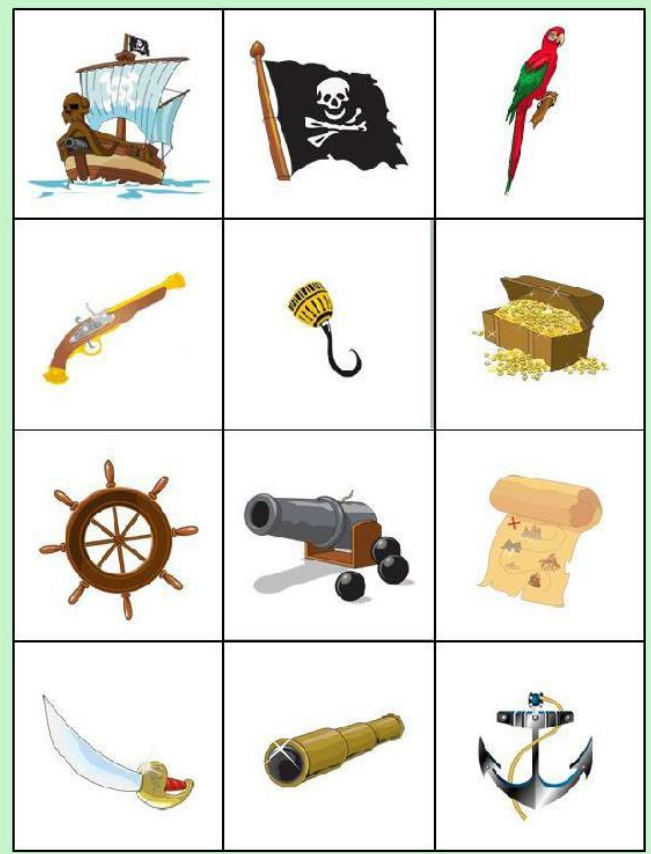

Vários jogos ou atividades podem ser propostas de forma a criar condições para a utilização das palavras que nomeiam as imagens. Fizemos, por exemplo, um jogo de memória no qual cada carta virada devia ser nomeada. Podemos igualmente propor labirintos nos quais devemos passar por vários objetos na ordem solicitada, ou então solicitar que cada criança desenhe a sua própria ilha do pirata usando pelo menos 3 ou 4 daquelas imagens. O uso repetido das palavras possibilita a internalização dos aspectos fonéticos e de algumas formas de uso. Pode-

${ }^{4}$ Chamados de imagiers em francês. 
se, desta forma, automatizar a produção oral das palavras que iriam emergir em outros contextos de uso.

Por meio do dicionário de imagens, podemos vincular, de forma direta, um som a uma imagem, que se torna, por um tempo determinado, a imagem referente. Posteriormente, com a abordagem de outros temas ou então simplesmente com o confronto cotidiano entre outras imagens e aquele som, amplia-se a rede de significados. A citação a seguir do filósofo MerleauPonty (2012) explicita esta questão ao escrever sobre o significado e o signo e a dinâmica que esta relação possui dentro da língua.

A língua dispõe de um certo número de signos fundamentais, arbitrariamente ligados a significações-chave; ela é capaz de compor qualquer significação nova a partir daquelas, portanto de dizê-las na mesma linguagem, e finalmente a expressão exprime porque reconduz todas as nossas experiências ao sistema de correspondências iniciais entre tal signo e tal significação, de que tomamos posse ao aprender a língua, e que, por sua vez, é absolutamente claro, porque nenhum pensamento permanece nas palavras, nenhuma palavra no puro pensamento de alguma coisa. (MERLEAU-PONTY, 2012, p. 30)

As palavras não devem, portanto, ser trabalhadas de forma descontextualizada. O contexto é fundamental na perspectiva sócio-interacionista adotada nesta reflexão. De nada adianta propor uma aquisição maciça e repetitiva de palavras se elas não ajudarem a compor frases que expressarão por sua vez ideias e pensamentos.

Por meio das palavras podemos acessar um tipo de apreensão da realidade relacionada à língua-cultura à qual está vinculada. É relevante ter em mente, portanto, que a escolha do tema e das palavras ou frases que serão escolhidas é em si um ato político e carregam em si um teor ideológico. Assumir este caráter ideológico e político é assumir a responsabilidade em promover um ensino que se quer crítico na concepção freiriana.

... se nos concentrarmos apenas na aquisição de aspectos léxico-gramaticais, pelo menos do modo como estes são comumente entendidos, em que não se verifica a maneira como se integram aos variados usos, não conseguiremos desvendar a relação linguagem-cultura, a forma como ela nos modifica: nós constituímos a linguagem e somos constituídos por ela, modificamos e somos modificados e, nesse jogo, vamos nos constituindo enquanto sujeitos únicos, singulares. (DEL RÉ, DE PAULA E MENDONÇA, 2014, pg. 19)

Quanto mais palavras a criança conhecer, mais instrumentalizada ela estará para tomar a palavra e expressar-se. Hagège escreve que antes de construir frases a criança aprende palavras e que é conveniente fazê-lo adquirir, quão mais cedo possível, o maior número de palavras, o 
que não quer de forma nenhuma dizer que deva-se ensinar palavras fora do seu contexto 5

(HAGÈGE, 2005, p. 66). É desejável, portanto, que a criança tenha acesso a certa diversidade de palavras em áreas e em assuntos que podem lhe ser úteis e relevantes para ela.

Por exemplo, além do léxico utilizado para contar histórias e acessar um repertório cultural literário importante no universo infantil, como é o caso do tema do pirata, das princesas, das bruxas, do circo, também existem aquelas palavras que permitem falar do cotidiano e de si. É o caso das partes do corpo, dos membros da família, das ações do cotidiano. Estas categorias lexicais não precisam ser trabalhadas de forma exclusiva, uma categoria por vez. Elas podem ser reagrupadas e progressivamente sobrepostas. No tema piratas, por exemplo, aproveitei para abordar as partes do corpo. No Anexo 1, estão as imagens encontradas na internet que serviram de suporte para este trabalho e que permitem ter uma ideia do trabalho desenvolvido.

Os suportes usados durante as aulas podem ser provenientes de livros ou sítios da internet. Gostaria, no entanto, de chamar uma atenção especial para o interesse na utilização de fotos tiradas das ou pelas crianças. Como já foi abordado logo acima, a imagem na qual a criança se reconhece permite uma maior apropriação do material e maior interesse por parte dos aprendizes. Por esta razão, consideramos desejável identificar e apresentar o repertório de palavras na e por meio das imagens das próprias crianças ou tiradas por elas. Esse é o caso, por exemplo, da foto tirada do cachorro Ratatouille ${ }^{6}$, acima, durante o tema Les animaux. Na aula em que recebemos a visita de Ratatouille, as crianças puderam brincar, observar, alimentar e tirar fotos do cachorro. A foto serviu de suporte na produção do material a ser usado durante a aula seguinte. Os aprendizes deviam identificar as partes do corpo do animal que tinham sido verbalizadas reiteradas vezes na aula anterior. Os alunos que já compreendiam as palavras foram colocados em situação de produção ativa da categoria lexical Partes do corpo dos animais. Após a verbalização eles deviam identificar as etiquetas com as palavras escritas e colá-las na folha. Por se tratar de dois alunos de idades diferentes cada um desenvolveu esta atividade de acordo com os seus conhecimentos de escrita e da relação letra/som. Henrique, de 7 anos por exemplo, leu as etiquetas. Guilherme, de 4 anos, identificou a primeira letra e associou-a a um som o que lhe permitiu identificar as palavras que estavam escritas. Neste exemplo podemos observar que a

\footnotetext{
${ }^{5}$ Tradução livre do original en francês: “En rappelant qu'avant de construire des phrases, l'enfant apprend des mots, et qu'il convient de lui en faire acquérir très tôt le plus possible, je ne veux nullement dire qu'il faille enseigner ces mots hors de tout contexte. »
} 
atividade concreta de manipulação criou condições para uma a atividade em papel que exigia um maior grau de abstração e conhecimento prévio.

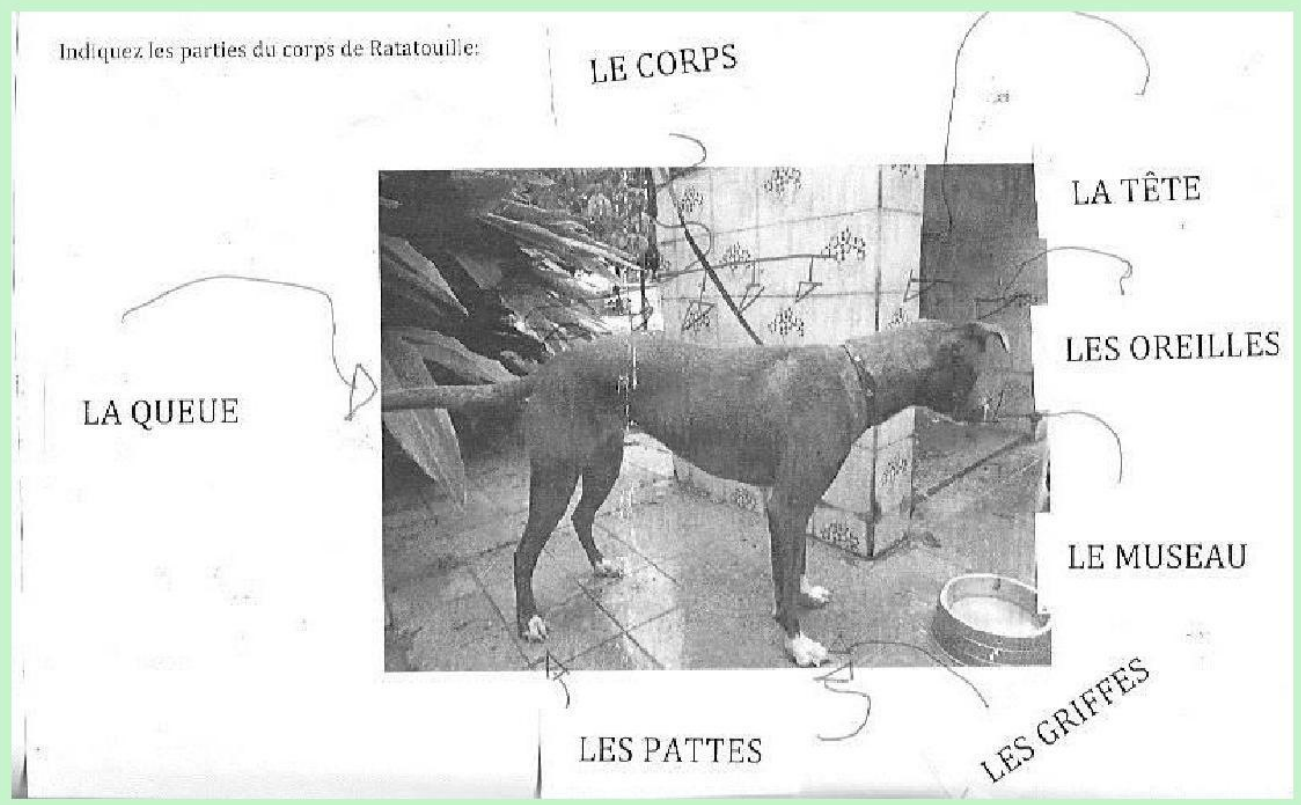

Podemos observar no exemplo acima como foi proporcionada a utilização de um mesmo campo lexical reiteradas vezes sem, para tanto, parecer artificial. Podemos, nós, professores, estimular e criar situações nas quais as crianças se veem impelidas a reutilizar aquilo que já foi abordado. É na reutilização que, aos poucos, a palavra vai se fazendo necessária, passando a fazer parte do acervo linguístico da criança. A foto a seguir, desta vez tirada durante o tema Pirates

(Piratas), vemos Guilherme e Henrique vestidos de pirata. Os elementos que podemos visualizar (espada, tapa-olho e chapéu) foram fabricados durante as aulas pelas crianças. Se, em uma atividade anterior, abordamos alguns objetos e elementos familiares ao universo dos piratas por meio de imagens retiradas da web, agora, podemos ver alguns deles compondo o personagem personificado pelo aprendiz. A criança pode utilizar o vocabulário aprendido para produzir uma frase a partir da observação da imagem. No caso da foto, a frase produzida foi: "Je suis un pirate parce que j'ai un cache-oeil, un chapeau de pirate et une épée." ("Eu sou um pirata por que eu tenho um tapa-olho, um chapéu de pirata e

${ }^{6}$ Ratatouille é o nome do meu cachorro de estimação. Após autorização dos pais dos alunos levei o cachouro para uma aula que serviu de base para desenvolver uma série de atividades 
uma espada.”). A frase foi retomada posteriormente no vídeo, no qual as crianças apresentam o desenho que fizeram de um pirata. ${ }^{7}$ Desta vez ao invés da primeira pessoa do singular, eu, os alunos utilizam a terceira pessoa, Mon pirate porte... (Meu pirata usa....) ou Il est un pirate... (ele é um pirata...).

Para além dos objetos que podem ser identificados pontualmente em uma imagem, como é o caso da espada, do chapéu e do tapa olho na representação acima, a imagem é uma importante ferramenta para abordar ações e sentimentos. Trata-se da terceira possibilidade listada acima. Menos identificáveis que os objetos, podemos encontrar alguma dificuldade em explicitar uma ação quando a imagem usada para tal está desvinculada da vivência dos aprendizes. Podemos, com facilidade, encontrar uma imagem que se refira ao verbo "cortar". O mesmo não pode ser dito, por exemplo, para uma ação como "esperar". Se a imagem utilizada remete a uma vivência do aprendiz, ela estará se remetendo a algo experienciado pela criança e, portanto, mais significativo. Ela saberá, por exemplo que, na foto em que a vemos parada em pé, o que estava acontecendo de fato é que ela estava esperando a sua vez para escorregar no escorregador. A imagem remeteria, então, à ação de esperar e não a outra. Esse vínculo que estabelecemos entre a palavra, ou a frase, e o real é fundamental porque solicita a memória do aprendiz, que revive o instante registrado e associa um sentimento e uma situação a uma expressão. Para exemplificar esse aspecto, temos a atividade de produção do chapéu de pirata. Na foto a seguir, vemos a criança em ação.

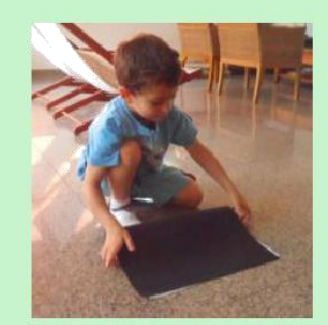

\begin{tabular}{|l|}
\hline PLIER \\
"Je plie le papier."
\end{tabular}
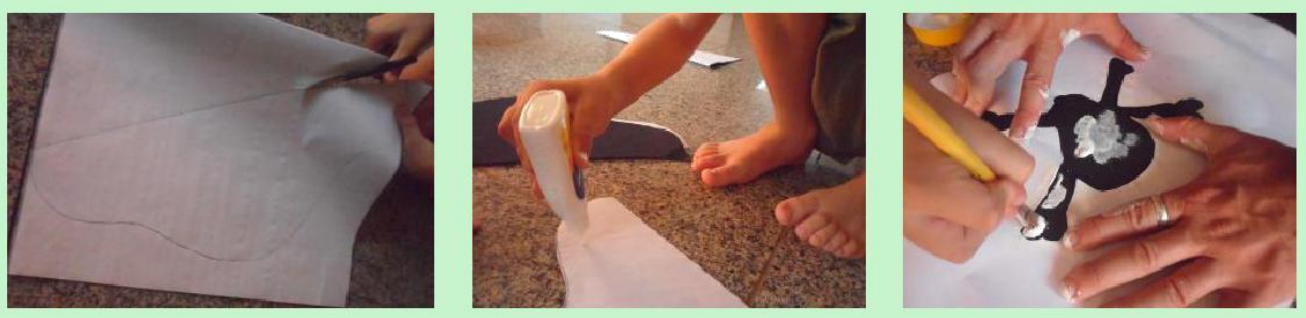

\begin{tabular}{|l|l|}
$\begin{array}{l}\text { DÉCOUPER } \\
\text { "Je découpe le chapeau." }\end{array}$ & $\begin{array}{l}\text { COLLER } \\
\text { "Je colle les deux côtés du } \\
\text { chapeau." }\end{array}$
\end{tabular}

TAPOTER

"Je peint la tête de mort en tapotant avec un peinceau 
Revista Letras Raras

ISSN: 2317-2347 - Vol. 6, Ano 4, No.1 - 2015

\begin{tabular}{|l|l|l|l|}
\hline & & & et de la peinture blanche." \\
\hline DOBRAR & $\begin{array}{l}\text { RECORTAR } \\
\text { "Eu dobro o papel." }\end{array}$ & $\begin{array}{l}\text { COLAR } \\
\text { "Eu colo as duas partes do o chapéu." } \\
\text { chapéu." }\end{array}$ & $\begin{array}{l}\text { BATER LEVEMENTE } \\
\text { "Eu pinto a caveira batendo } \\
\text { levemente com um pincel e } \\
\text { com tinta branca." }\end{array}$ \\
\hline
\end{tabular}

A criança executou estas atividades para produzir o seu próprio chapéu de pirata. Ao ver as imagens elas remetem às suas ações e permitem uma produção oral com contexto e coerência pelos elementos implícitos que carrega.

Antes de abordar o quarto aspecto, gostaria de fazer uma última consideração levando em conta os aspectos já mencionados. Como podemos constatar, utilizei as palavras "reempregar", "reutilizar", "reinvestir" algumas vezes, fazendo referência ao movimento em espiral, que permite a apreensão de um elemento ou de uma estrutura linguística. O movimento em espiral significa as palavras, as estruturas e as vivências. É reempregando e reutilizando que ajustamos significados, posturas, procedimentos e escolhas e que consolidamos conhecimentos. A título de exemplo, citarei a sequência didática Os Animais do Meu Jardim. Como suporte propulsor dessa sequência, assistimos ao desenho animado Milou. No episódio escolhido, dois coelhos irmãos pegam alguns animais do jardim para fazer um zoológico dentro do quarto, um zoológico com os animais do jardim.

Com base no desenho animado, várias atividades foram desenvolvidas durante as aulas. No decorrer dessas atividades que envolviam, entre outras coisas, uma aula no jardim, uma aula na cozinha, desenho, fabricação de objetos e até a construção do nosso próprio zoológico com os animais do jardim, assistimos mais duas vezes o desenho Milou. Foi no decorrer desse processo que o desenho Milou ganhou significado. Na última vez em que foi assistido, depois de todas as atividades terem sido desenvolvidas, os alunos puderam perceber quão imbricadas estavam as atividades desenvolvidas e que podiam parecer desconexas no momento em que estavam sendo vividas. A exclamação dos alunos "Como a gente!" fazendo alusão ao zoológico com os animais do jardim que os coelhos tinham feito no desenho é indício dessa compreensão que se consolida em processo.

Ainda fazendo referência às imagens das crianças ou tiradas pelas crianças em situação de aprendizagem, gostaria de explicitar dois tipos de abordagens que podem ser desenvolvidas. Como vimos anteriormente, uma foto das crianças em situação pode ser bastante útil na 
apreensão e na compreensão de palavras que expressem e nomeiem objetos, ações ou sentimentos. Esse mesmo material pode servir de matéria-prima para o trabalho com pronomes e tempos verbais. Abordarei cada um deles a seguir.

Dentre as competências a serem trabalhadas e adquiridas durante a educação infantil, está a de saber utilizar o pronome "eu". A utilização dos pronomes certamente se dá em ritmos diferentes segundo a criança e as culturas. A cultura e a pressão social exercidas sobre a criança serão determinantes nos comportamentos e na linguagem (VYGOSTKY, 2008). A apropriação dos pronomes é um processo que depende também da percepção da própria criança enquanto indivíduo dentro de um grupo. Podemos ver, nas primeiras fases do desenvolvimento infantil, um comportamento majoritariamente egocêntrico. Nessa fase, o pronome "nós" dificilmente será dito pela criança. O "eu" e o "meu”, ao contrário, são largamente utilizados. A seguir veremos um exemplo de como podemos promover o uso e aquisição dos pronomes.

Nas fotos acima, vemos as crianças fazendo o chapéu do pirata. Nela, além das ações e do material, podemos identificar as pessoas. Ao se ver na foto, a criança pode, ao buscar identificar a pessoa que aparece ali, dizer o próprio nome ao invés do pronome que indica a primeira pessoa do singular. Este é o momento em que por meio da mediação do adulto é possível introduzir o pronome "eu". Com o auxílio das imagens vamos, fornecendo, aos aprendizes, os pronomes que permitem distinguir as pessoas. Na foto em que vemos o irmão, não utilizaremos mais o pronome “eu", mas o pronome "ele". Ao ver em uma terceira imagem, dos dois juntos, podemos então abordar o pronome "nós".

É relevante, por fazer parte do desenvolvimento cognitivo da criança, saber se o aprendiz já reconhece os pronomes na LM (Língua Materna). Conhecer o nível de expressão oral da criança na LM é importante, por exemplo, para os pronomes. Caso o aprendiz já recorra a esse elemento linguístico na LM, o professor apresenta um paralelo na LE. Se não for um elemento linguístico apreendido e utilizado na LM, na LE, o processo é um pouco mais complexo e exige uma maior reflexão diante de cada caso.

Uma última observação sobre os pronomes se faz necessária. Utilizarei como exemplo o pronome "eu" para levantar o aspecto a seguir. Ao ver uma foto com a imagem de Guilherme, por exemplo, Guilherme dirá: "Guilherme”. O professor, buscando introduzir a utilização do pronome "eu", pode recorrer a um feedback que diz baixinho "Sou eu". O dizer baixinho, neste caso, busca explicitar aquilo que deveria ser a fala da criança. Não é a professora quem diz, mas o 
aprendiz. Podemos perceber rapidamente que, apesar da utilidade que esta estratégia possui, pode existir uma certa confusão que perturba a própria noção à qual remete o pronome "eu". Se não sou eu, por que digo “eu”?

É buscando encontrar outra possibilidade para essa situação que faço a sugestão a seguir. O professor espera que Guilherme, ao ver uma foto sua, diga, por exemplo: "Sou eu." Caso não o faça, o professor pega sua própria foto e diz "Sou eu." Espera-se que a criança perceba o paralelo entre a professora que se vê e diz "Sou eu" e "Eu me vejo e digo "sou eu" e possa estabelecer um paralelo semelhante entre a sua imagem e a fala. Podemos afirmar que a confusão não mais existirá e que a verbalização do "eu” pela criança não será a repetição do feedback proposto pela professora em voz baixa, mas, sim, a apropriação de noção mais complexa que a utilização do pronome suscita.

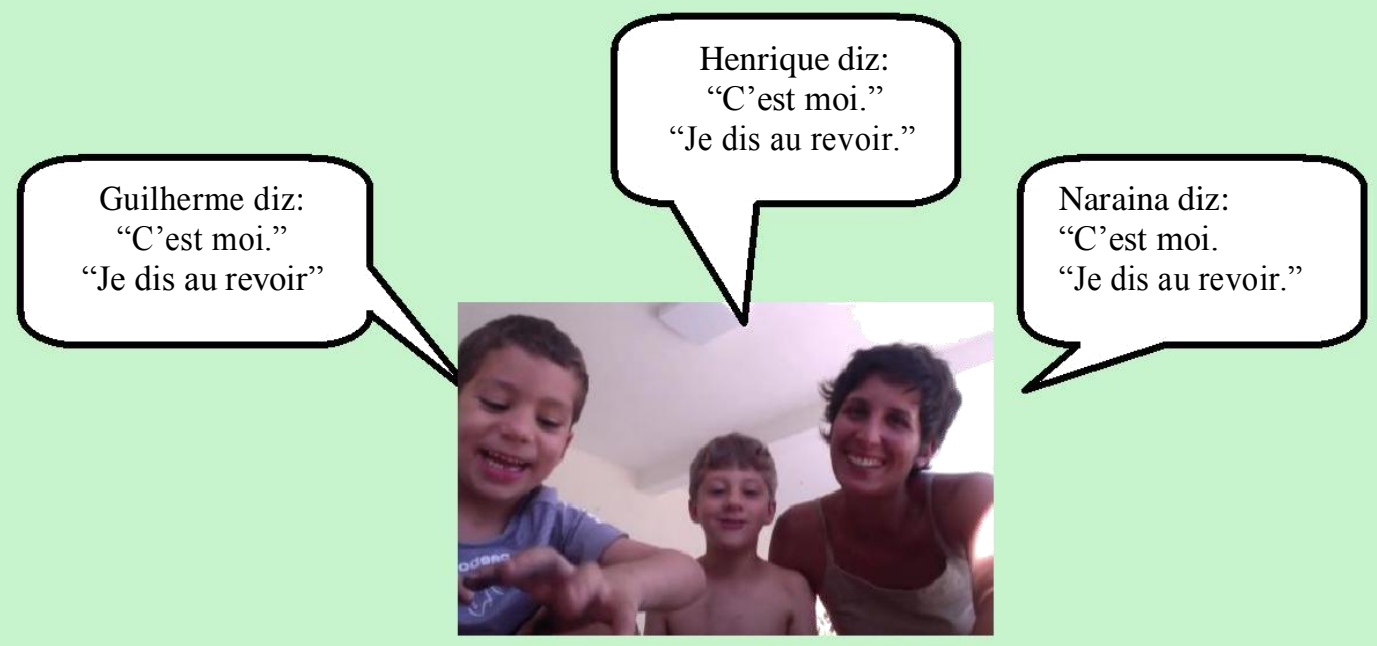

As imagens podem, igualmente, proporcionar um trabalho refletido do uso dos tempos verbais. No momento em que estamos realizando as atividades, as verbalizações são feitas no presente com enunciados do tipo "Pegue a tesoura.", "Vamos cortar o papel.", "Precisamos pintar a espada.", "Olha a Ratatouille! Ela está visitando o jardim.” A visualização das imagens, por sua

${ }^{8}$ Como podemos reparar no exemplo abaixo, existe uma distinção em francês entre os pronomes pessoais retos empregados como sujeito e como predicativo do sujeito. No exemplo dado em português, "sou eu", a palavra "eu", para essa mesma frase em francês, não corresponde ao 
vez, remete ao acontecido no passado. Podemos, portanto, acessar um acontecimento compartilhado pelos participantes e revivê-lo, desta vez, fazendo as formulações no passado: "Eu peguei a tesoura para cortar o papel."

O futuro é, frequentemente, abordado na estruturação do tempo. Quando uma mesma atividade é executada repetidas vezes, podemos fazer alusão a ela por meio da imagem. Por exemplo, se, com frequência, existe o momento contação de história ou leitura de livro, podemos escolher uma imagem que represente esse momento. A imagem servirá de intermédio para a utilização do futuro:

"Qu'est-ce qu'on va faire maintenant?” (“O que vamos fazer agora?”) “On va lire un livre." (“Nós vamos ler um livro.”)

No vídeo do Milou, que tinha sido visualizado diversas vezes, por exemplo, era possível antecipar os acontecimentos produzindo frases no futuro: "Ils vont construire un zoo avec les animaux du jardin” (Eles vão construir um zoológico dos animais do jardim”.

A imagem pode ser, portanto, utilizada para estruturar os tempos passado, presente e futuro. Um mesmo acontecimento pode ser o suporte para esse trabalho refletido e controlado sobre os tempos verbais.

O quadro a seguir propõem uma esquematização dos aspectos linguísticos explorados por meio das imagens e que foram abordados até o presente momento. Trata-se de possibilidades de utilização e não é, portanto, exaustiva ou completa, cabendo sempre outras contribuições.

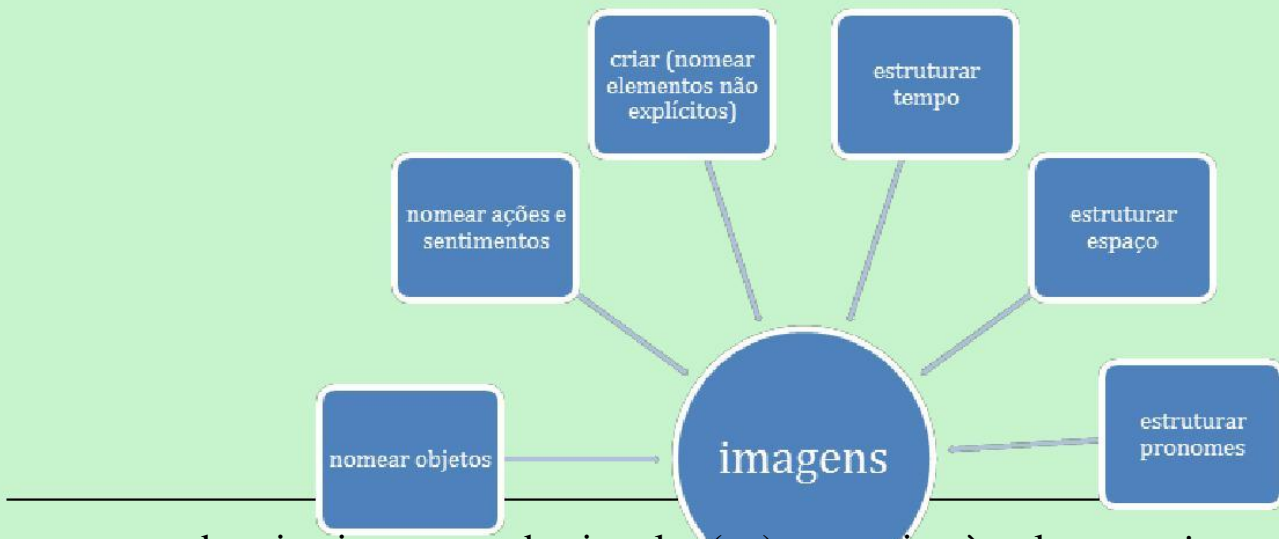

pronome da primeira pessoa do singular (eu), mas, sim, à palavra moi, que é um pronome reto do predicativo do sujeito. 
Gráfico 1: As imagens

Fonte : A AUTORA

Uma vez desenvolvidos os aspectos acima devo fazer a distinção entre as imagens gravadas durante as atividades e aquelas que servem de suporte para um trabalho linguístico mais controlado. No primeiro caso, as atividades desenvolvidas colocam as crianças em ação, momento em que a gravação de imagens é feita. Por exemplo, durante a atividade na qual cada criança fez o seu chapéu de pirata foram tiradas fotos que serviriam para produzir posteriormente uma apresentação PowerPoint intitulada Le Chapeau du Pirate (O Chapéu do Pirata). Ou ainda durante a visita da Ratatouille foram gravadas imagens que seriam editados no vídeo intitulado Ratatouille no qual vemos as crianças brincando com o cachorro. Este material visual constitui matéria prima para uma produção oral controlada e estruturada.

No momento da gravação do áudio, o vídeo passa a ser a moldura que enquadra um momento pedagógico preciso e de duração definida e no qual elementos estruturais ou discursivos podem ser solicitados mais explicitamente. No vídeo Ratatouille, fica claro, por exemplo, que, além das partes do corpo dos animais, também estamos trabalhando o verbos de ação ter (avoir), correr (courrir), pegar (attraper), tentar( essayer de) e as frases afirmativas.. O objetivo do professor é que os aprendizes formulem frases como as seguintes: "J'essaye d'attraper Ratatouille" (Eu tento pegar Ratatouille), "Elle court vite”. ("Ela corre rápido).

O que é importante salientar neste ponto é que o vídeo permite enquadrar uma atividade em que se solicita um uso mais controlado e refletido da língua. Com o mesmo ponto de partida, por exemplo, a visita da Ratatouille, vários tipos de competências e habilidades podem ser trabalhadas. Podemos imaginar que, em um primeiro momento, o objetivo era observar, manipular, interagir com o cachorro, falar sobre ele e sobre as suas ações. Nesta etapa percebemos a manipulação e a utilização do corpo. Em um segundo momento, trabalhamos as palavras percebidas e que foram apresentadas separadamente como importantes para falar sobre aquilo que foi vivido. As fotos impressas da Ratatouille, por exemplo, servem de suporte para colar os nomes das partes do corpo do cachorro, que foram exploradas individualmente. Posteriormente, observamos as imagens editadas e gravamos as falas das crianças, nas quais as palavras trabalhadas pontualmente aparecem, desta vez, inseridas em um enunciado, em um 
discurso e em que a utilização refletida da língua passa a ser o principal objetivo. Por fim, visualizamos o vídeo com o material auditivo e visual e o postamos no blog.

A gravação do material de áudio, a visualização do material audiovisual e a utilização de imagens e vídeos retirados de diversas fontes são exemplos de momentos em que a imagem está presente. Em cada uma delas (e em tantas mais), podemos explorar a imagem de forma diferente. Utilizamos esses recursos para:

1) iniciar a abordagem de algum tema ou assunto e perceber o conhecimento prévio das crianças;

2) explorar aspectos que visem a alcançar os objetivos fixados;

3) reempregar aquilo que foi trabalhado em contextos diferentes;

4) concluir, eventualmente, um tema em que percebemos o que e como o conteúdo trabalhado foi apreendido pelas crianças. ${ }^{9}$

Uma vez abordados os quatro aspectos apresentados no início deste subcapítulo, gostaria de abordar um último aspecto da imagem: a criação. Diante de uma mesma imagem, o aprendiz pode ser interpelado por várias informações que ali estão explícitas ou implícitas. Os diferentes níveis de percepção e de produções que decorrerão daquela visualização dependem e estão diretamente vinculados à experiência e à vivência de cada um. É esse potencial que eu chamo de criador. Mesmo que buscando abordar um aspecto preciso, o aprendiz sempre terá a liberdade de explorar e de fazer surgir algum aspecto que lhe é absolutamente individual. Mais uma vez, ao professor, atento, pode perceber as tentativas e as vontades do aluno para transformá-las em objeto troca e de diálogo.

\section{Conclusão}

Descrevemos quatro possíveis abordagens pedagógicas da imagem com o objetivo de trabalhar a produção oral do aluno na língua estrangeira. Os tipos de atividades propostos visam promover a produção, construir sentido e suprir as lacunas linguísticas da expressão oral. Rojo (2012): prática situada, instrução aberta, enquadramento crítico, prática transformada. 
As imagens são uma importante ferramenta pedagógica já que possibilitam estabelecer e manter um vínculo visual entre aquilo que foi executado pelos alunos e a sua verbalização em um tempo estendido. Este vínculo é propício para a expressão oral do aprendiz uma vez que o mesmo terá algo a dizer a partir visualização da imagem de uma situação vivida. O professor por sua vez aproveita este momento de expressão genuína para estruturar a língua oral.

As abordagens propostas focaram a produção oral do francês como língua estrangeira. Podemos, no entanto, utilizar a mesma didática para qualquer outra língua estrangeira e inclusive na estruturação da língua materna.

\section{Referências}

BAKHTIN, M. Marxismo e filosofia da linguagem. São Paulo: Ed. HUCITEC, 1992.

DEL RÉ, DE PAULA e MENDONÇA. Aquisição da linguagem e estudos bakhtinianos do discurso. In:. Del Ré, A., de Paula, L., Mendonça, M. C. A linguagem da criança. Um olhar bakhtiniano. São Paulo: Contexto: 2014, pág. 17-30.

HAGÈGE, C. L'enfant aux deux langues. Paris: Odile Jacob, 2005.

KUYUMJIAN, N. M. M. O Ensino do Francês como Língua Estrangeira para crianças Brasileiras: uma proposta metodológica. Dissertação de mestrado. Brasília - UnB/PGLA, 2014. Disponível em http://hdl.handle.net/10482/17744

MARCUSCHI, Da fala para a escrita: atividades de retextualização. 10. ed. São Paulo: Cortez, 2010.

MERLEAU-PONTY, M. A prosa do mundo. São Paulo: Cosac Naify, 2012

VYGOTSKI, L. Pensamento e linguagem. São Paulo: Martins Fontes, 2008, $4^{\mathrm{a}}$ Ed. 